\title{
Transitions across agriculture-savannah edges: Why did the rodent cross the edge?
}

\author{
Joanna Raye Ennis \\ University of Florida
}

Faculty mentor: James Austin, Wildlife Ecology and Conservation

\begin{abstract}
Human-induced landscape alteration by agriculture is ubiquitous and impacts ecological processes and ecosystem services. The boundary between altered and native vegetation (hereafter edges) can create anthropogenic barriers for wildlife movement. Wildlife movement response to edges is dependent on landscape and functional group characteristics that could affect spatial behavior, population dynamics, dispersal, diversity, gene flow, and nutrient distribution. Few studies exist on small-mammal functional group movement response to edges. This study analyzed the effect of altered land use on movement response in savannah generalist Mastomys natalensis and specialist Lemniscomys rosalia. Each species was live-trapped for 2 months at 8 sites, across 2 boundary classes - homestead agriculture vs. savannah and commercial agricultural vs. savannah. 12 individuals of each species were tracked and translocated at each transect with alternating treatments. Mastomys natalensis showed no significant edge crossing trend (42\% average). In agriculture to savannah translocations, $M$. natalensis showed increased average step lengths and significant net squared displacement (R2n). Mastomys natalensis had tighter R2n in agriculture habitats. Lemniscomys rosalia had varied movement response to edges compared to $M$. natalensis and exhibited trends of moving out of altered lands (67\% stayed in savannah, $66 \%$ crossed back into savannah, and $80 \%$ avoided edge crossing in control). These results support the a priori hypothesis that altered land-use areas greatly impact specialists moving across the edge, but only minimally impact generalist movements. Mastomys natalensis results possibly indicate lower resource utilization or predator avoidance in savannah but show no trend in edge crossings. Results from L. rosalia possibly indicate their inability to use altered lands or became trapped in savannah habitat. Our results show that altered landscapes can affect small mammal movements.

Keywords: small mammal, functional groups, animal movement, translocation, edges, barriers, habitat fragmentation, landscape alteration.
\end{abstract}

\section{Introduction}

Human-induced wildland alterations for agriculture are ubiquitous and commonly implicated in compromising vertebrate biodiversity. These alterations can impede ecological processes and ecosystem services (Crist et al. 2017, Bailey et al. 2016, Hurst et al. 2013). Landscape fragmentation and alteration, such as crop cultivation, can form anthropogenic barriers where native vegetation communities and altered lands meet (hereafter edges), consequently hindering 
wildlife movement (Crooks et at. 2006, Donald 2004). Human population growth in Southern Africa is growing at $2 \%$ annually (Burian et al. 2018), resulting in further degradation of native vegetation communities via fragmentation and alteration (Maltitz et al. 2018). The 2 dominant forms of agriculture in Eswatini are traditional homestead farms (heterogeneous with intermixed natural cover; Alkemade 2012, Fahrig etal. 2011). These resultant landscapes consist of a mosaic of native vegetation edges that are suitable for some wildlife species but hostile to others (Dytham 1996).

Movement is a ubiquitous behavior for all wildlife; and is driven by physiological, behavioral, biotic, and abiotic traits (Panzacchi 2010, Crooks et at. 2006). Wildlife movements are determined by many interacting parameters including movement rate, direction, turning frequency, and angle. A chosen movement heeds the potential costs and benefits that vary with landscape structure and species' traits. Individuals balance increased mortality by predation and energy expenditure with reduced intra-specific competition and higher resource quality and quantity benefits at a new location. Benefits that spur wildlife movement may depend on their ability to cross an edge between different cover types. These encountered edges will either expedite or hinder further movement, which can directly or indirectly affect its overall fitness. Variation in the movement response to edges by an individual is both landscape and functionalgroup dependent (Fahrig 2007, Crooks et at. 2006). Edge composition influences species differently and can vary across anthropogenic land uses and by functional traits (i.e., physiology, behavior, and life history). Ultimately, the landscape and the species itself can be impacted (Allen 2016).

Small mammals are frequently chosen as biological indicators due to factors including ease of observation and identification, and ease of capture and marking. Small mammals also have small home ranges, can be measured and sampled quickly, and are inexpensive to study. Their high reproductive rates can result in rapid responses to habitat and plant-community-structure change. Small mammals can serve as ecosystem engineers, keystone species, prey species, nutrient cycle promoters, and seed predators (Avenant 2000). Therefore, small mammals are an ideal taxon to study the effects of landscape-edge alterations on wildlife movement and behavior. However, although these responses are integral parts of behavioral and ecological processes (Liedvogel et al. 2013, Fahrig 2007), there is currently a dearth of research on movement response to edges for different small mammal functional groups. 
The present study focused on 2 functional groups of African savannah mammals: generalist and specialist species. Specialist species have a low dispersal ability, which decreases their abundance in a mosaic landscape, due to their physiology, behavior, and life history. Conversely, generalist species have a high dispersal rate in mosaic landscapes (Fahrig 2001). Small-mammal omnivores often have behavioral traits and ecological tolerances that enable them to move across edges and hence between varying habitats (Skinner \& Chinimba, 2005). Alternatively, smallmammal granivores and herbivores have evolved to thrive in specific habitats, creating difficulty in movement across edges into different altered landscapes (Panzacchi 2010). Other factors can prevent or enable a species to move across edges, including sex, age, size, and predator avoidance (Allen 2016). Comparing the movement of species in different small-mammal functional groups in response to edges has not been explicitly modeled and has only been viewed as a function of environmental factors (Panzacchi 2010, Fahrig 2007). Understanding which functional groups are affected by landscape alterations and how their movements change in these landscapes is key to predicting responses to future landscape alterations (Bricker et al. 2010, Hurst et al. 2014).

This study's objectives were to understand how small mammals belonging to different functional groups-Mastomys natalensis (generalist) and Lemniscomys rosalia (specialist) move across edges in the landscape mosaic lowveld of Eswatini, through small mammal translocations. Mastomys natalensis is a generalist omnivore that often inhabits agriculture such as sugarcane (Hurst et al. 2013, Hurst et al. 2014). Mastomys natalensis is nocturnal, with a high tolerance of varying habitats, and is often considered a pest in agriculture and homesteads (Skinner \& Chinimba 2005). Lemniscomys rosalia is a mixed granivory-herbivory specialist that is uncommon in agricultural areas (Hurst et al. 2013, Hurst et al. 2014). Lemniscomys rosalia is diurnal, crepuscular, and occupies a wide variety of native vegetation types (Skinner \& Chinimba 2005).

The study focused on wildland-homestead agriculture edges and wildland-commercial agriculture edges to examine how heterogenous landscapes affect small mammal movement characteristics in different functional groups. It was predicted the studied species within the 2 functional groups would respond to edges in a way that reflects the ecology of the functional group after translocation. It was predicted that the generalist species (i.e., $M$. natalensis) would move freely across the edge, whereas the specialist species (i.e., L. rosalia) would not. 


\section{Methods}

\section{Study Area}

The research was conducted in the lowveld region of northeastern Eswatini that borders the Lubombo Mountains, Mbuluzi River, and Mozambique. The basecamp was the Savannah Research Center in Mbuluzi Game Reserve $26.1564^{\circ}$ S, $31.9824^{\circ}$ E. Lowveld altitude ranges 150-400m above sea level (Monadjem 2005). Mean monthly temperature in the wet season (October to March) is $25^{\circ} \mathrm{C}$ and $19^{\circ} \mathrm{C}$ in the dry season (April to September), with a mean rainfall of $575 \mathrm{~mm}$ and $130 \mathrm{~mm}$ in the wet and dry season, respectively (Monadjem \& Bamford 2009). This lowveld region consists of Acacia nigrescens-Sclerocarya birrea savannah, broadleaved woodland, and riverine forest that supports rich wildlife biodiversity (Monadjem 1999, Mbuluzi Game Reserve). Within the study region, all commercial sugarcane plantations and homestead farms adjoined wildland conservation areas.

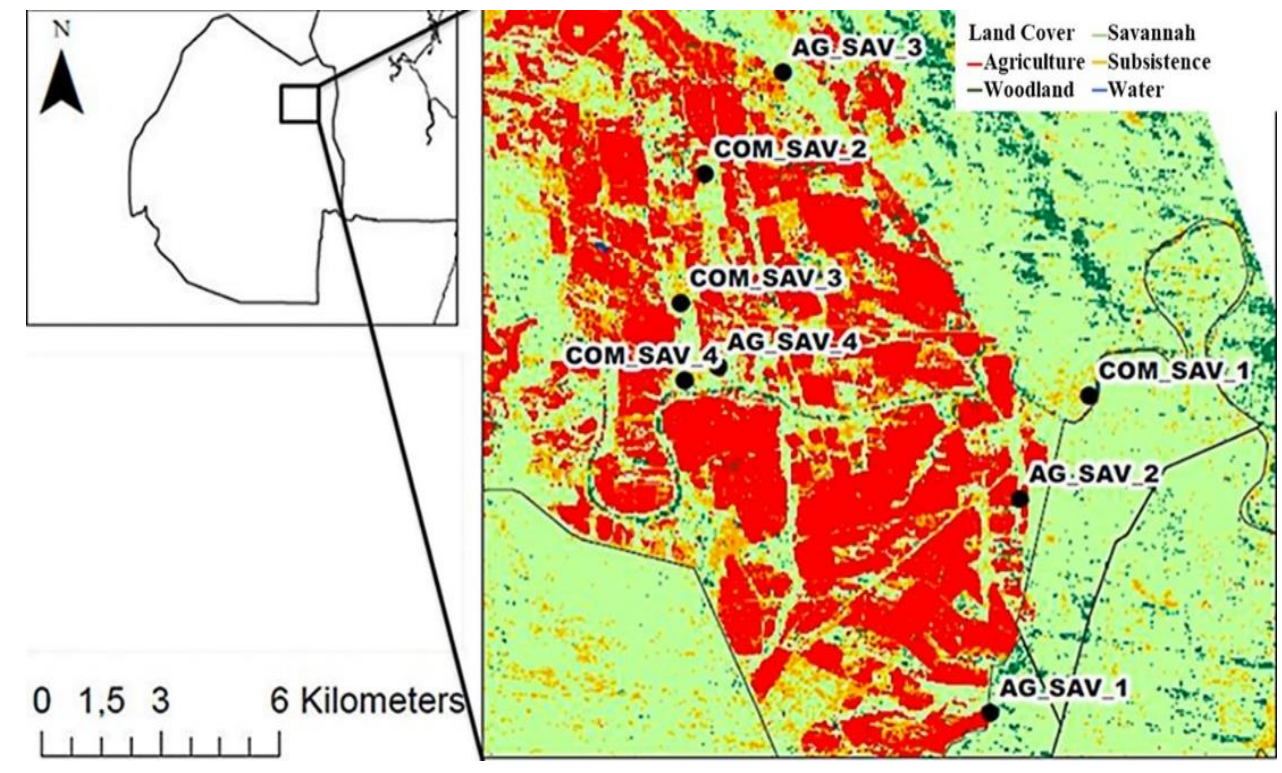

Fig. 1. 4 replications of homestead agriculture to savannah (Com_Sav) and commercial agriculture to savannah (Ag_Sav), depicted of northeastern Eswatini.

\section{Sampling Design}

The study examined small mammal movements at 2 boundary classes — homestead agriculture versus savannah and commercial agricultural versus savannah (Fig. 1, Fig. 2.A.B), at 4 replicate sites each. At each site replicate, a paired trapping transect of $300 \mathrm{~m}$ by $4 \mathrm{~m}$ were identified, where small mammal sampling occurred. A GPS was used to mark the transect borders. 
Each transect had 30 traps placed $2 \mathrm{~m}$ from each side of the edge boundary, totaling 60 traps per boundary class. Traps were GPS-marked and spaced at $10 \mathrm{~m}$ intervals.
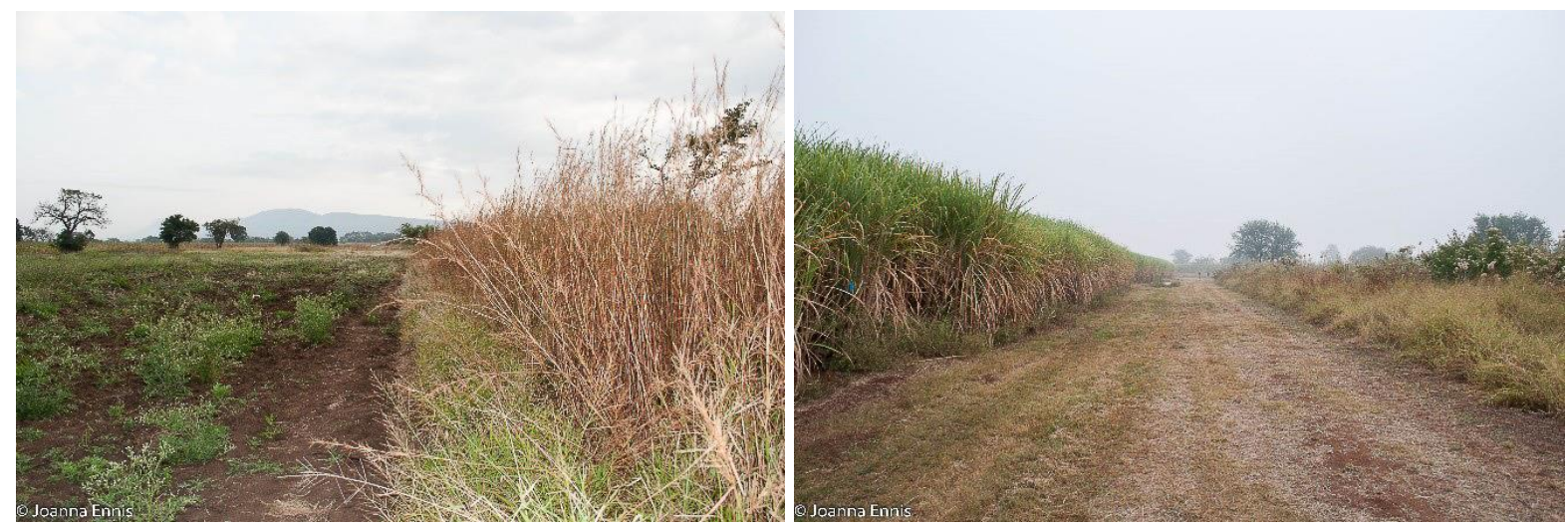

Fig. 2. There are 2 boundary classes: (A) Homestead agriculture versus savannah (left). (B) Commercial agricultural versus savannah (right).

\section{Capture and Processing Methods}

Small mammals were trapped from June-July 2017 with Sherman live-traps $(16 \mathrm{~cm}$ x $6.5 \mathrm{~cm} \mathrm{x}$ $5.5 \mathrm{~cm}$ : H.B. Sherman Trap Inc. Tallahassee, Florida USA) baited with peanut butter and oats. The traps were checked at 0400 and 1600 based on M. natalensis and L. rosalia activity patterns, respectively nocturnal and crepuscular/ diurnal.

Once captured, small mammals were identified and only kept for translocation if they were $M$. natalensis or $L$. rosalia. Individuals were given unique ID and fluorescent powder color. Mass (g), sex, age, trap ID, captured habitat, translocation habitat, site ID, weather, and air temperature were recorded. Trapping and handling procedures conformed to guidelines established by the American Society of Mammologists (Sikes et. Al. 2016) and were approved by the University of Florida's Institutional Animal Care and Use Committee (Protocol 201509045).

\section{Translocation and Release Methods}

12 individuals of each species were translocated at each boundary class at a distance of $100 \mathrm{~m}$ from their trapping location (Fig. 3.A.B). 3 individuals of each species were translocated within the habitat in which they were captured, and 3 individuals were translocated to the habitat on the opposing side of the edge. Fluorescent powder (Day-Glo Color Corp. Cleveland, Ohio USA) of different colors was used to follow individual movements. Each small mammal was dusted in a pan, receiving a thick fluorescent powder coating, before release. 


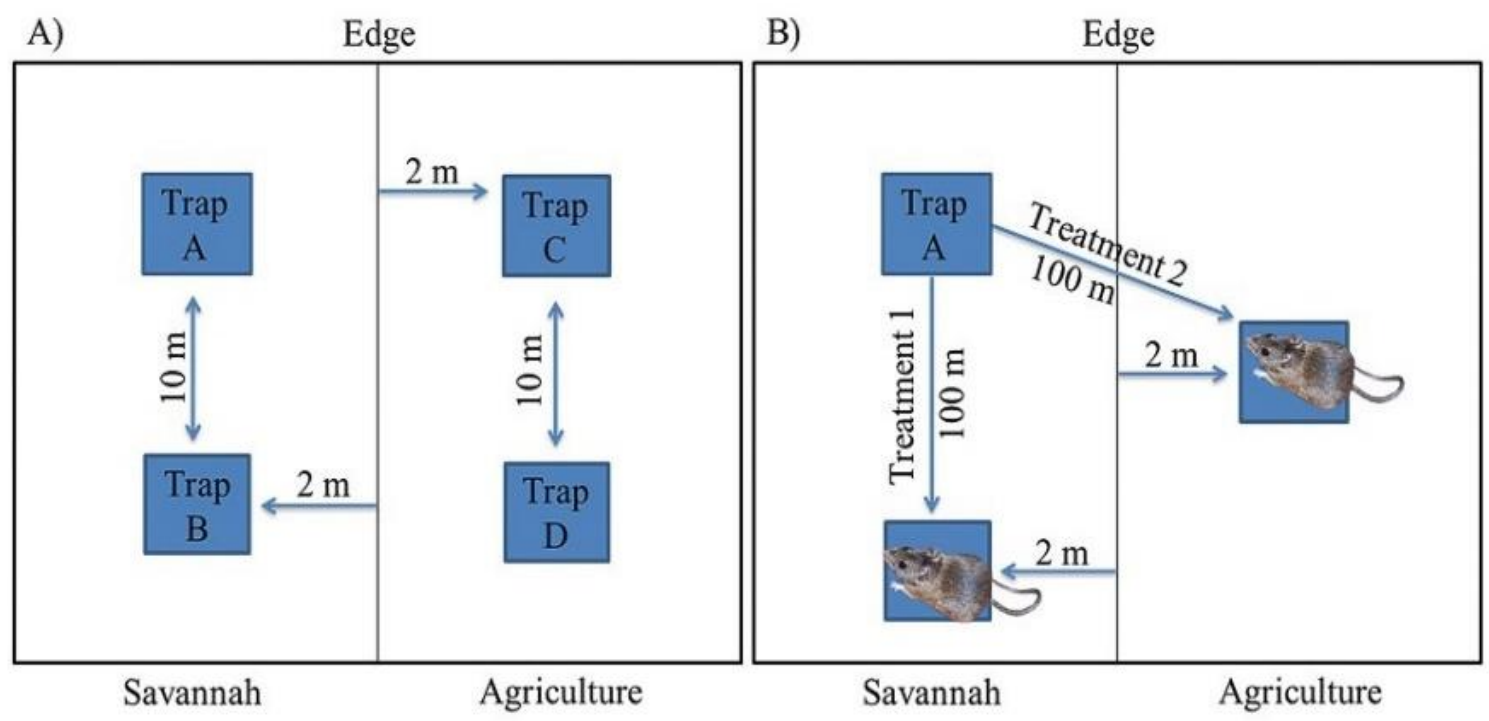

Fig. 3. (A) Paired trapping transect: each box represents a trap placed in either savannah or agriculture habitat types. The traps are spaced 10-m apart and $2 \mathrm{~m}$ from edge. (B) Translocation: illustrates 2 treatment options for trap A.

To reduce human influence on small-mammal movement, individuals were placed on a tile (37 $\mathrm{cm} \times 37 \mathrm{~cm}$ ) under a corrugated plastic holding apparatus $(31 \mathrm{~cm}$ length $\times 31 \mathrm{~cm}$ width $\times 20 \mathrm{~cm}$ height) through a cutout door (10 cm long x $8.5 \mathrm{~cm}$ wide; Fig. 4.A). This apparatus was attached to a 3 legged metal tripod $(90 \mathrm{~cm}$ long) operated by a pulley and rope $(450 \mathrm{~cm})$. Standing $440 \mathrm{~cm}$ from the apparatus, the small mammal was kept inside for 30 seconds before pulling the string to lift it for release. The apparatus was kept raised for 5 minutes to ensure dispersal. An hour after release, the apparatus was removed and the movements were flagged utilizing a black light to follow its pathway (Long 2012). Each flag was placed $1 \mathrm{~m}$ apart along the individual's route, obtaining a minimum track of $30 \mathrm{~m}$ in total distance (Fig. 4.B). At dawn, each change of direction was recorded by taking a measure and bearing. Flags and alternated fluorescent powder color were retained at each translocation site to avoid crossover. 

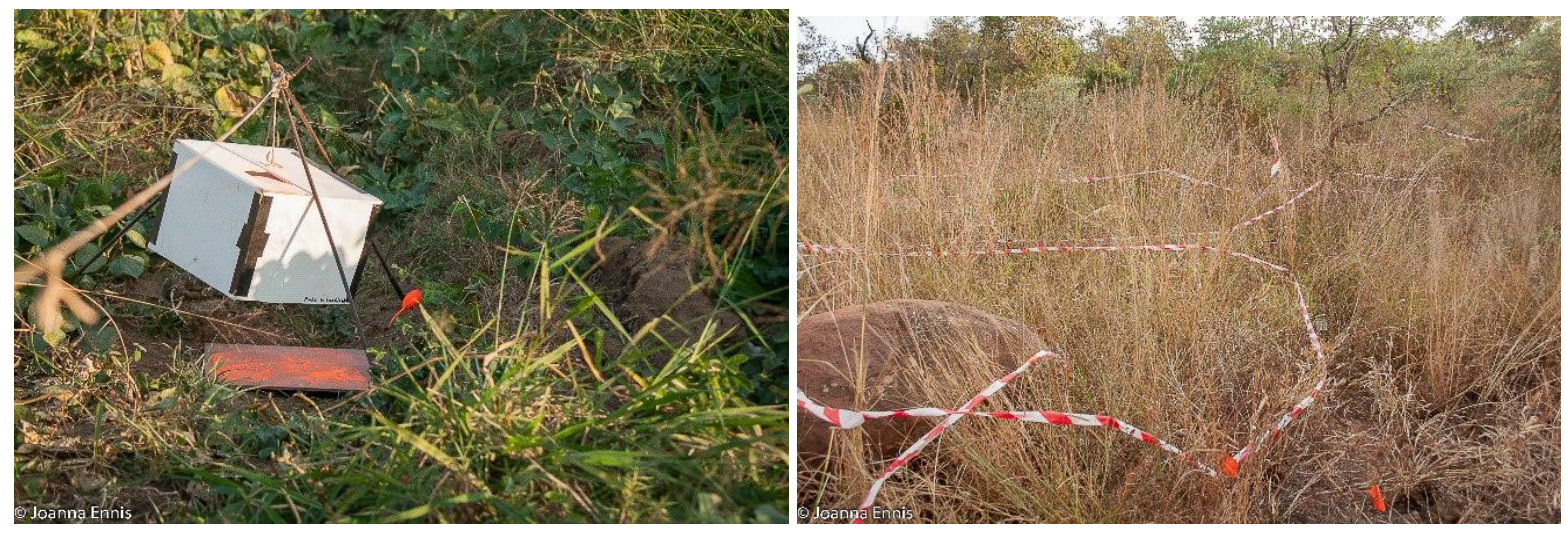

Fig. 4. (A) The holding apparatus with the tile, depicting the release of a small mammal (left). (B) A single small mammal track with flagging along its pathway (right).

\section{Data Analysis}

Tracks were converted to trajectories in $\mathrm{R}$ Adehabitat package and were recorded if the small mammal tracks had crossed the edge or not. Binomial mixed effects models were used to compare species regarding edge crossings. The average step length and net squared displacement (R2n) were calculated to describe $M$. natalensis tracks with TT4 models; consisting of grouped controls and 3 treatment types.

\section{Results}

108 individual tracks were collected from M. natalensis and L. rosalia. Tracks $<30 \mathrm{~m}$ in length were removed from analysis, leaving 89 tracks for analysis - 17 L. rosalia and 72 M. natalensis tracks. Lemniscomys rosalia tracks were 1127-15952 cm long and averaged $5180 \mathrm{~cm}$. Mastomys natalensis tracks were $841-12123 \mathrm{~cm}$ long and averaged $3750 \mathrm{~cm}$.

\section{Edge Crossing Statistics}

Only 33\% (1 individual) of L. rosalia captured in agricultural habitat crossed the edge and moved back to the original capture habitat. There was no discernible difference between commercial or homestead agriculture capture habitat. Alternatively, when L. rosalia was captured in savannah habitat and translocated into commercial or homestead agriculture habitats, $66 \%$ (6 individuals) returned to savannah habitat. When L. rosalia was originally captured in the same habitat to which it was translocated, $80 \%$ (4 individuals) avoided edge crossings, regardless of abutting vegetative community. Mastomys natalensis showed no significant edge crossing 
trend, averaging $42 \%$ (30 individuals) for the 3 possible scenarios. Their movement across edges showed no relation to the habitat type of translocation or capture site.

\section{Movement Trajectories-Average Step Length and Net Squared Displacement}

There was no difference between M. natalensis and L. rosalia trajectories. Mastomys natalensis had a higher probability of crossing the edge $-\beta$ (estimate $)=0.08$ : $\mathrm{CI}$ (confidence intervals $)=-1.28-1.47$-versus $L$. rosalia, but the difference was not significant. Calculation of the number of edge crossings showed L. rosalia crossed more times in the commercial and homestead agriculture edge habitats to savannah edge habitats than other treatments, with a trend between savannah to commercial and homestead agriculture edge habitats $-\beta=1.52$ : $\mathrm{CI}=-1.29$ 7.8 (Fig. 5.A, Fig. 6.B).
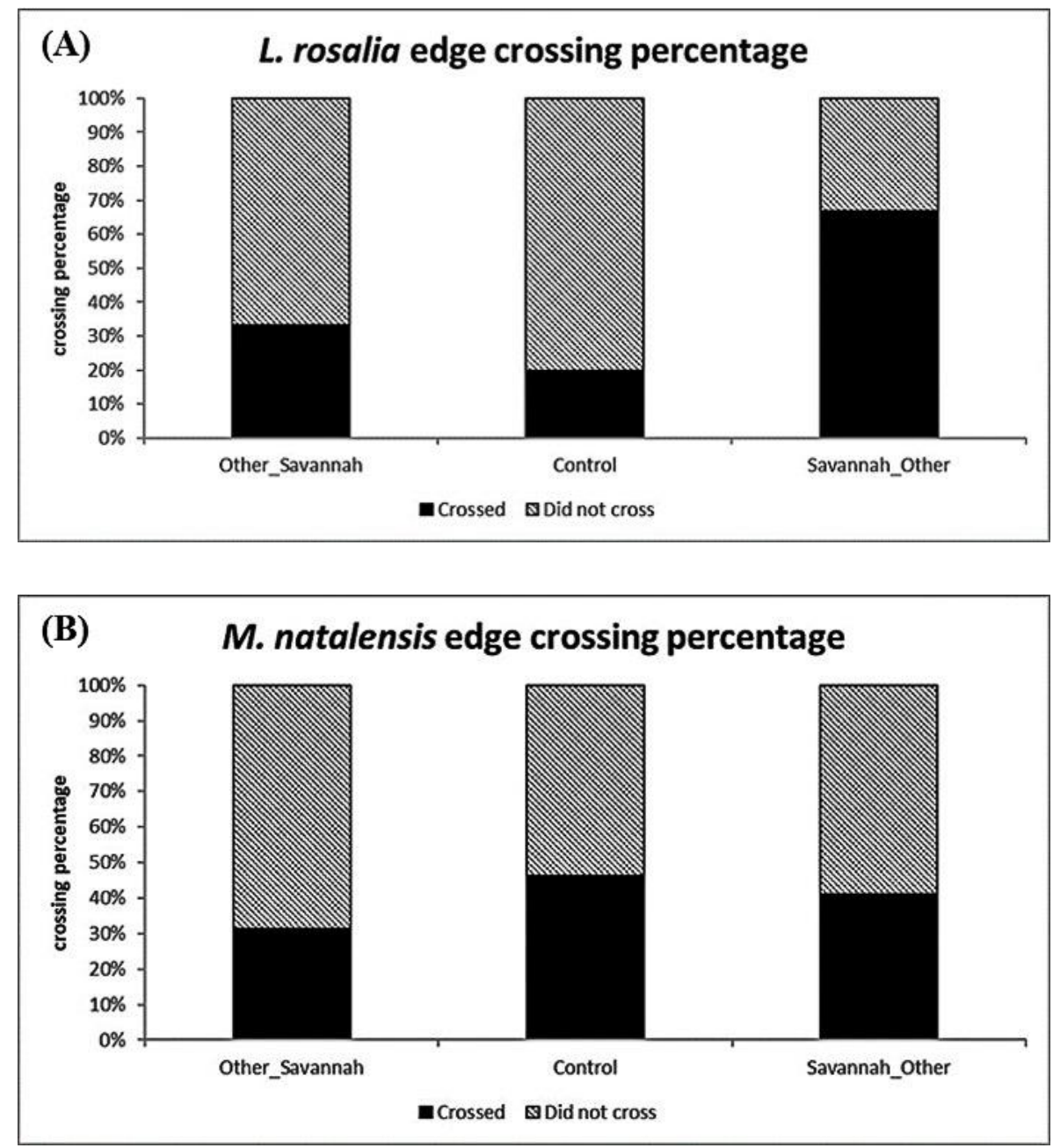

Fig. 5. Percent of (A) Lemniscomys rosalia (B) Mastomys natalensis edge crossing in 3 treatment types. Other refers to commercial and homestead agriculture habitat, savannah refers to savannah habitat, and control refers to the treatment-savannah to savannah. 
Mastomys natalensis showed no trend in the number of edge crossings but showed a trend for staying in commercial and homestead agricultural edge habitats $-\beta=0.5$ : CI $-1.12-2.16$ (Fig. 5.B).

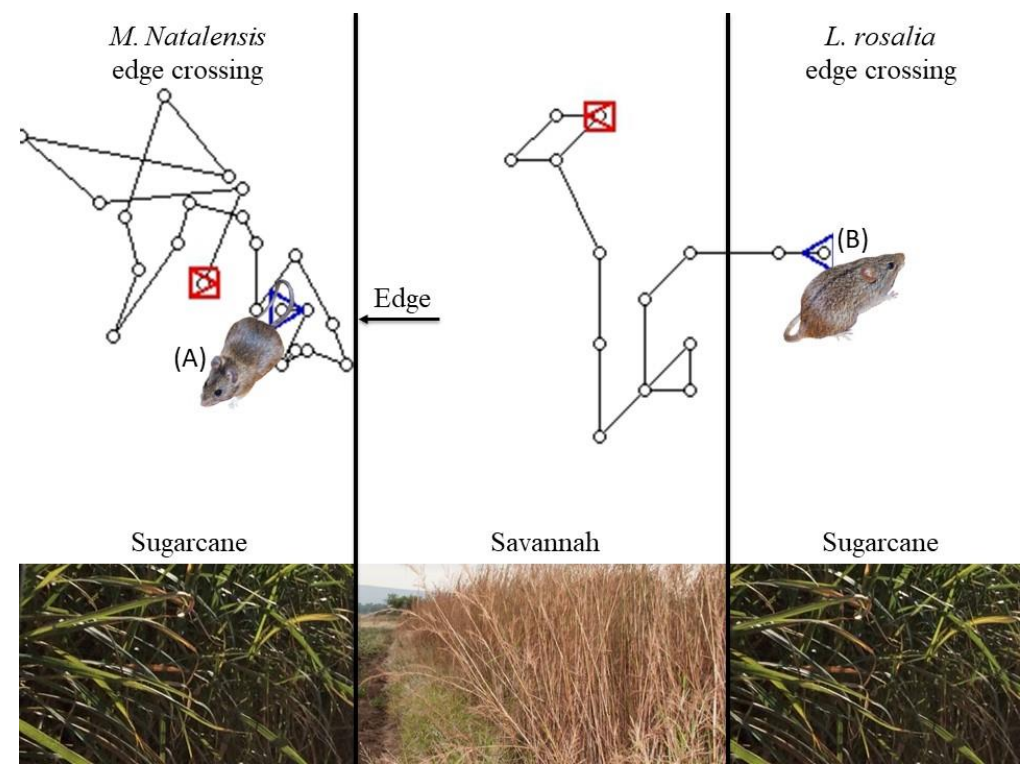

Fig. 6. (A) Mastomys natalensis translocation into commercial agriculture-no edge crossing into commercial agriculture. (B) Lemniscomys rosalia translocation into commercial agriculture-crossed edge back to savannah. Blue triangle equals the release point and red square equals the end of the track.

Mastomys natalensis track characteristics had a lower average step length $(\beta=0.054$ : CI -1.850.87; Fig. 7.B) and a higher R2n (0.58: CI -0.35-1.51; Fig. 7.A) than L. rosalia, but neither were significant. In treatment commercial agriculture to savannah edge habitat ( $\beta=2.16$ : CI 0.16-4.14), showed increased step lengths and significance ( $\beta=2.16$ : CI 0.16-4.14; Fig. 7.B). Mastomys natalensis $\mathrm{R} 2 \mathrm{n}$ of treatment commercial agriculture to savannah edge habitat showed significance as well ( $\beta=1.75$ : CI 0.13-3.35; Fig. 7.A). 

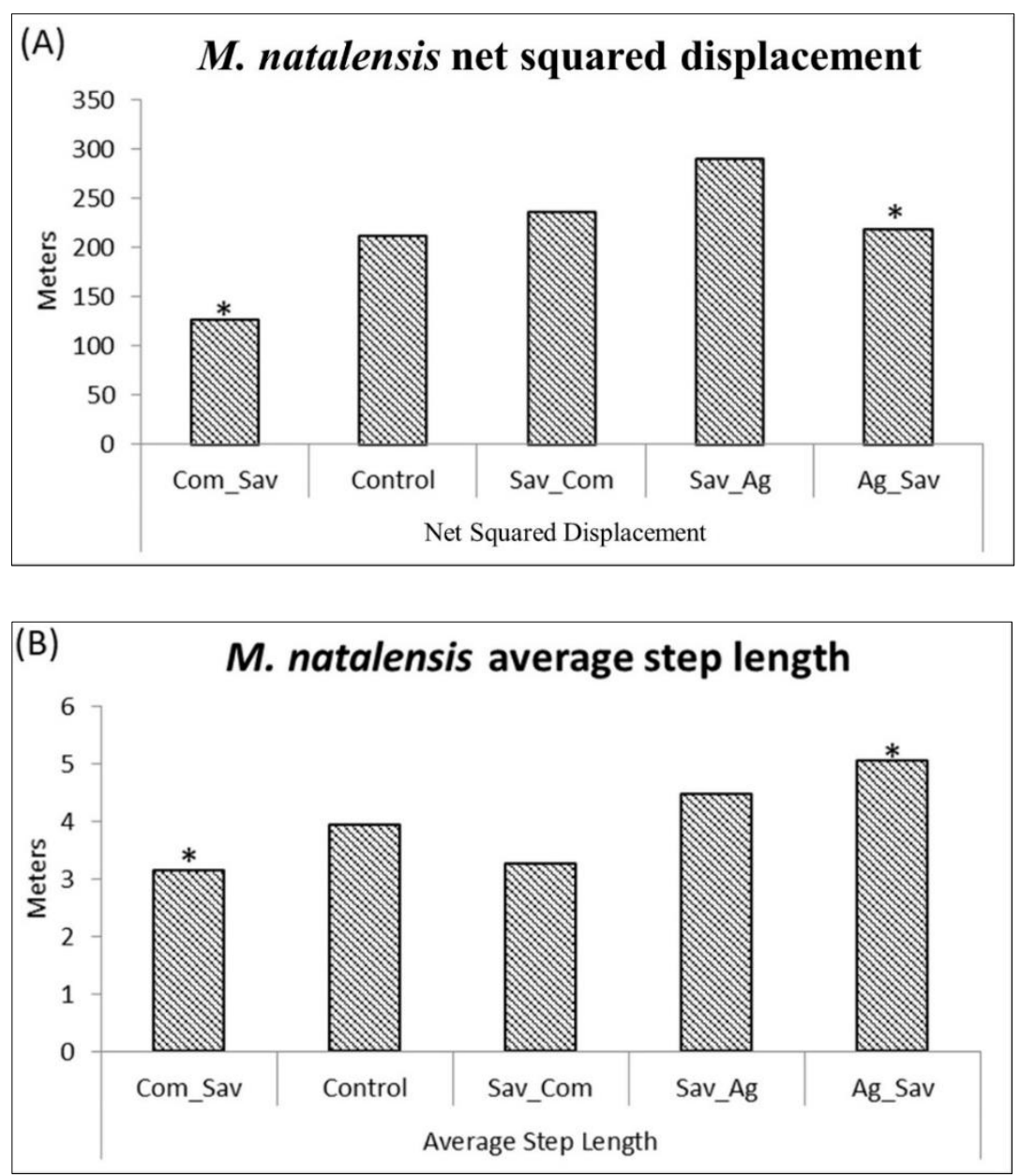

Fig. 7. Mastomys natalensis (A) R2n and (B) average step length in 5 different treatment types-homestead agriculture to savannah (Com_Sav), savannah to savannah (Control), savannah to homestead agriculture (Sav_Com), savannah to commercial agriculture (Sav_Ag), and commercial agriculture to savannah (Ag_Sav). * significant result.

\section{Discussion}

The results support the a priori hypotheses that $M$. natalensis, an omnivorous generalist, would move similarly across edges in all 3 treatments due to its behavioral traits and ecological tolerances (Skinner \& Chinimba 2005). Mastomys natalensis stayed in commercial and homestead agricultural habitats more often, possibly due to the abundance of food and cover that was available to them. Meanwhile, L. rosalia individuals showed tendency of edge crossings with translocation into any agriculture habitat, showing a high chance of returning to savannah habitat. In the control, L. rosalia showed a trend of avoiding edge crossings, i.e., if trapped and translocated within agriculture they remained in agriculture. It was concluded that specialized species, such as L. rosalia, want to move out of altered landscapes or may become trapped 
within them due to their ecological and behavioral factors (Panzacchi 2010). This shows a potential negative association with future habitat change.

Mastomys natalensis movement trajectory results with TT4 models, showed increased average step length and significant R2n in agriculture to savannah translocations (Fig. 7.A.B, Fig. 8.A.B). Low resource availability increased the average step length as small mammals searched for higher-quality habitats (Fahrig 2007). Conversely, when M. natalensis were translocated to commercial or homestead agriculture, they showed tighter movement patterns near the release point, potentially because they utilized the landscape for food and cover more efficiently compared to the savannah (Fig. 8.A).

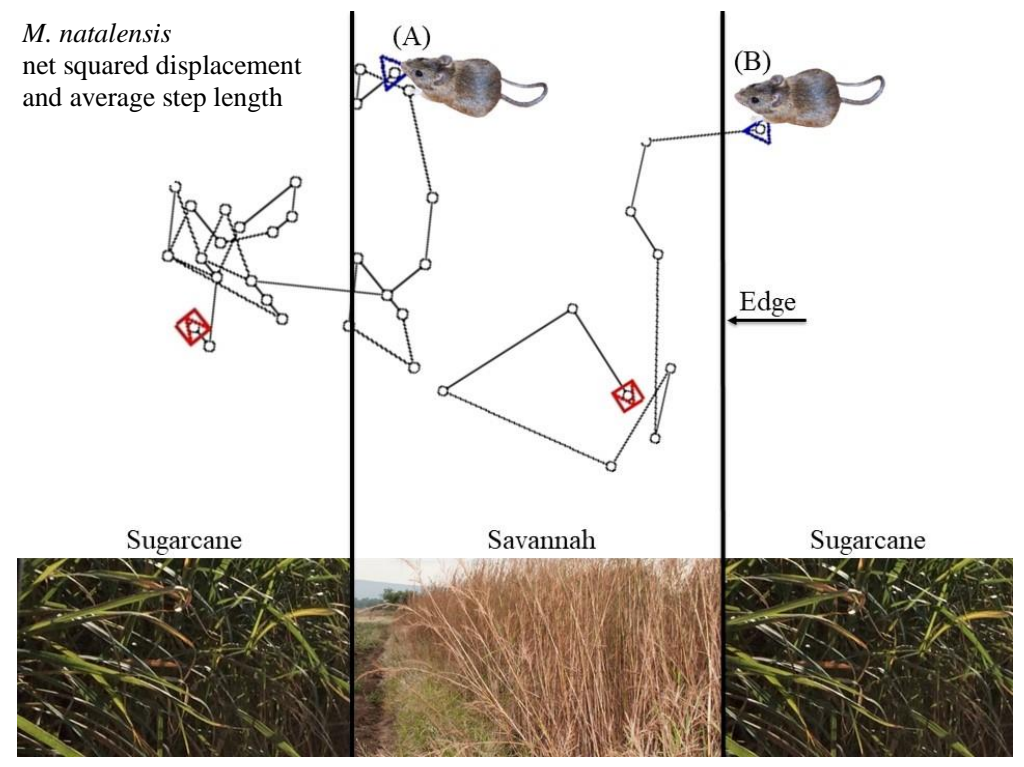

Fig. 8. Mastomys natalensis (A) net squared displacement (R2n)—savannah to commercial agriculture (Sav_Ag), showed increased R2n in commercial agriculture. Mastomys natalensis $(\mathbf{B})$ average step length — commercial agriculture to savannah (Ag_Sav), showed increased average step lengths and significance in savannah. Blue triangle equals release point and red square equals the end of the track.

Although most analyses for L. rosalia were not conducted due to small sample size, L. rosalia still showed varied responses toward edges where $M$. natalensis did not. In future studies, it would be interesting to continue movement research on L. rosalia along the same protocols. Additional trapping deeper into the edge, and expansion of study sites would need to be done to achieve the desired sample size to conduct additional L. rosalia analysis. 


\section{Management Implications}

Landscape alterations are ubiquitous and create a moving target for species evolution. However, other studies, e.g., Gilchrist, Huey \& Serra 2001; Gilchrist et al. 2004; O'Steen, Cullum \& Bennett 2002, have shown that functional groups with short generation times, like small-mammal generalists in mosaic landscapes, could evolve fast enough to pace landscape alterations if the selective pressure is high enough. In most cases, landscape alterations are too quick for species movement evolution- e.g., small mammal specialists. Additionally, habitat loss from landscape alterations further curtails the evolutionary ability from decreased population sizes (Fahrig 2007).

The results of this study support the a priori hypothesis that commercial and homestead agriculture had minimal impact on generalists, such as $M$. natalensis, while impacted movements of specialized species, such as L. rosalia. The analysis revealed that specialists showed varied movement responses towards the 3 treatments, where generalists did not. These findings indicate that small mammal movements may be affected or changed by altered landscapes. Elsewhere, this has resulted in cascading effects that have altered vegetative and faunal communities (Bricker et al. 2010, Hurst et al. 2014), resulting in altered small mammal connectivity, evolution, specialized species isolation, and diversity.

\section{Acknowledgements}

This material is based upon work supported by the National Science Foundation under Grant No.1459882. This project was also supported the University of Florida, University of Eswatini, All Out Africa, Mbuluzi Game Reserve, and Savannah Research Center. This project would have not been possible without the input, time, and invaluable contribution from J. D. Austin, C. Reynolds, R. A. McCleery, A. Monadjem, R. J. Fletcher, K. A. Sayler, and S. M. Wisely, along with field support from IRES 2017 cohort.

\section{References}

Alkemade, R., Reid, R. S., van den Berg, M., de Leeuw, J., \& Jeuken, M. (2013). Assessing the impacts of livestock production on biodiversity in rangeland ecosystems. Proceedings of the National Academy of Sciences of the United States of America, 110(52), 20900-20905. doi:10.1073/pnas.1011013108

Allen, A. M., Mansson, J., Sand, H., Malmsten, J., Ericsson, G., \& Singh, N. J. (2016a). Scaling up movements: from individual space use to population patterns. Ecosphere, 7(10), 16. doi:10.1002/ecs 2.1524 
Allen, A. M., Mansson, J., Sand, H., Malmsten, J., Ericsson, G., \& Singh, N. J. (2016b). Scaling up movements: from individual space use to population patterns. Ecosphere, 7(10), 16. doi:10.1002/ecs2.1524

Avenant, N. L. (2000). Small mammal community characteristics as indicators of ecological disturbance in the Willem Pretorius Nature Reserve, Free State, South Africa. South African Journal of Wildlife Research, 30(1), 26-33.

Bailey, K. M., McCleery, R. A., Binford, M. W., \& Zweig, C. (2016). Land-cover change within and around protected areas in a biodiversity hotspot. Journal of Land Use Science, 11(2), 154-176. doi:10.1080/1747423x.2015.1086905

Bricker, M., Pearson, D., \& Maron, J. (2010). Small-mammal seed predation limits the recruitment and abundance of two perennial grassland forbs. Ecology, 91(1), 85-92. doi:10.1890/08-1773.1

Burian, A., Karaya, R., Wernersson, J. E. V., Egberth, M., Lokorwa, B., \& Nyberg, G. (2019). A community-based evaluation of population growth and agro-pastoralist resilience in Sub-Saharan drylands. Environmental Science \& Policy, 92, 323-330. doi:10.1016/j.envsci.2018.10.021

Cane Growing in South Africa. n.d. SASA | Cane Growing in SA. Retrieved from http://www.sasa.org.za/sugar_industry/CaneGrowinginSA.aspx.

Cleland, J. (2013). World population growth; past, present and future. Environmental and Resource Economics, 55, 543-554.

Crist, E., Mora, C., \& Engelman, R. (2017). The interaction of human population, food production, and biodiversity protection. Science, 356(6335), 260-264. doi:10.1126/science.aal2011

Crooks, K., \& M. Sanjayan. (2006). Connectivity conservation. Cambridge University Press, Cambridge, England, United Kingdom.

Donald, P. F. (2004). Biodiversity impacts of some agricultural commodity production systems. Conservation Biology, 18(1), 17-37. doi:10.1111/j.1523-1739.2004.01803.x

Dytham, C. \& R. T. T. Forman. (1996). Land mosaics: The ecology of landscapes and regions. The Journal of Ecology, 84, 787.

Esterhuizen, D. (2015). The supply and demand of sugar in Swaziland. Retrieved from https://gain.fas.usda.gov/Recent\%20GAIN\%20Publications/Sugar\%20Annual_Pretoria_Swazilan d_4-20-2015.pdf.

Fahrig, L. (2007). Non-optimal animal movement in human-altered landscapes. Functional Ecology, 21(6), 1003-1015. doi:10.1111/j.1365-2435.2007.01326.x

Fahrig, L. (2001). How much habitat is enough? Biological Conservation, 100(1), 65-74.

Fahrig, L., Baudry, J., Brotons, L., Burel, F. G., Crist, T. O., Fuller, R. J., . . Martin, J. L. (2011). Functional landscape heterogeneity and animal biodiversity in agricultural landscapes. Ecology Letters, 14(2), 101-112. doi:10.1111/j.1461-0248.2010.01559.x 
Flynn, D. F. B., Gogol-Prokurat, M., Nogeire, T., Molinari, N., Richers, B. T., Lin, B. B., . . DeClerck, F. (2009). Loss of functional diversity under land use intensification across multiple taxa. Ecology Letters, 12(1), 22-33. doi:10.1111/j.1461-0248.2008.01255.x

Hurst, Z. M. (2010). Effects of intensive agriculture on small mammal communities in and adjacent to conservation areas in Swaziland (Master of Science Thesis). Texas A\&M University.

Hurst, Z. M., McCleery, R. A., Collier, B. A., Fletcher, R. J., Silvy, N. J., Taylor, P. J., \& Monadjem, A. (2013). Dynamic Edge Effects in Small Mammal Communities across a ConservationAgricultural Interface in Swaziland. Plos One, 8(9), 9. doi:10.1371/journal.pone.0074520

Hurst, Z. M., McCleery, R. A., Collier, B. A., Silvy, N. J., Taylor, P. J., \& Monadjem, A. (2014). Linking changes in small mammal communities to ecosystem functions in an agricultural landscape. Mammalian Biology, 79(1), 17-23. doi:10.1016/j.mambio.2013.08.008

Jewitt, D., Goodman, P. S., Erasmus, B. F. N., O'Connor, T. G., \& Witkowski, E. T. F. (2015). Systematic land-cover change in KwaZulu-Natal, South Africa: Implications for biodiversity. South African Journal of Science, 111(9-10), 9.

Johnson, A. R., Wiens, J. A., Milne, B. T., \& Crist, T. O. (1992). Animal movements and populationdynamics in heterogeneous landscapes. Landscape Ecology, 7(1), 63-75. doi:10.1007/bf02573958

Liedvogel, M., B. B. Chapman, R. Muheim, \& S. Åkesson. (2013). The behavioral ecology of animal movement: reflections upon potential synergies. Animal Migration, 1.

Long, A. K., Bailey, K., Greene, D. U., Tye, C., Parr, C., Lepage, H. K., . . McCleery, R. A. (2013). Multi-scale habitat selection of Mus minutoides in the Lowveld of Swaziland. African Journal of Ecology, 51(3), 493-500. doi:10.1111/aje.12062

Maltitz, V.M., Henley, G. Ogg, M., Samboko, P. C., Gasparatos, A., Read, M., ... Ahmed, A. (2018). Institutional arrangements of outgrower sugarcane production in Southern Africa. Development Southern Africa, 1-23. doi:10.1080/0376835x.2018.1527215

Mbuluzi Game Reserve. n.d. Mbuluzi Game Reserve. Retrieved from http://www.thekingdomofswaziland.com/pages/attractions/the_attraction.asp?AttractionsID=39.

Monadjem, A. (1997). Stomach contents of 19 species of small mammals from Swaziland. South African Journal of Zoology, 32(1), 23-26.

Monadjem, A., \& Bamford, A. J. (2009). Influence of rainfall on timing and success of reproduction in Marabou Storks Leptoptilos crumeniferus. Ibis, 151(2), 344-351. doi:10.1111/j.1474919X.2009.00912.x

Monadjem, A. (1999). Biodiversity and Conservation. Biodiversity and Conservation, 8, 223-237.

Panzacchi, M., Linnell, J. D. C., Melis, C., Odden, M., Odden, J., Gorini, L., \& Andersen, R. (2010). Effect of land-use on small mammal abundance and diversity in a forest-farmland mosaic landscape in south-eastern Norway. Forest Ecology and Management, 259(8), 1536-1545. doi:10.1016/j.foreco.2010.01.030 
Ries, L., \& Sisk, T. D. (2004). A predictive model of edge effects. Ecology, 85(11), 2917-2926. doi:10.1890/03-8021

Sikes, R. S., and the Animal Care and Use Committee of the American Society of Mammologists. (2016). 2016 Guidelines of the American Society of Mammologists for the use of wild mammals in research and education. Journal of Mammalogy. 97, 663-688.

Skinner, J. D., C. T. Chimimba, \& C. Abbott. (2005). The mammals of the southern African subregion. Cambridge University Press, Cambridge. 